Research Article

\title{
Community Involvement and Perceptions of the Community-Based Health Planning and Services (CHPS) Strategy for Improving Health Outcomes in Ghana: Quantitative Comparative Evidence from Two System Learning Districts of the CHPS+ Project
}

\author{
Margaret Kweku, ${ }^{1}$ Hubert Amu ${ }^{D},{ }^{1}$ Martin Adjuik, ${ }^{1}$ Emmanuel Manu ${ }^{\mathbb{D}},{ }^{1}$ \\ Fortress Yayra Aku, ${ }^{1}$ Elvis Enowbeyang Tarkang, ' Joyce Komesuor, \\ Geoffrey Adebayo Asalu, ${ }^{1}$ Norbert Ndaah Amuna, ${ }^{1}$ Laud Ampomah Boateng, \\ Justine Sefakor Alornyo, ${ }^{2}$ Roland Glover, ${ }^{2}$ Ayaga A. Bawah, ${ }^{3}$ Timothy Letsa, \\ John Koku Awoonor-Williams, ${ }^{4}$ S. Patrick Kachur, ${ }^{5}$ James F. Phillips, ${ }^{5}$ \\ and John Owusu Gyapong ${ }^{6}$
}

\footnotetext{
${ }^{1}$ School of Public Health, University of Health and Allied Sciences, Hohoe, Ghana

${ }^{2}$ Volta Regional Health Directorate, Ghana Health Service, Ho, Ghana

${ }^{3}$ Regional Institute of Population Studies, University of Ghana, Legon, Ghana

${ }^{4}$ Policy Planning Monitoring and Evaluation Division, Ghana Health Service, Accra, Ghana

${ }^{5}$ Mailman School of Public Health, Columbia University, New York, USA

${ }^{6}$ Office of the Vice Chancellor, University of Health and Allied Sciences, Ho, Ghana
}

Correspondence should be addressed to Hubert Amu; hamu@uhas.edu.gh

Received 22 June 2019; Accepted 6 April 2020; Published 7 May 2020

Academic Editor: Carol J. Burns

Copyright (c) 2020 Margaret Kweku et al. This is an open access article distributed under the Creative Commons Attribution License, which permits unrestricted use, distribution, and reproduction in any medium, provided the original work is properly cited.

\footnotetext{
Background. The Community-based Health Planning and Services (CHPS) initiative is Ghana's flagship strategy for achieving universal health coverage (UHC). Community involvement in and perceptions of CHPS capacity to improve health outcomes of communities are examined. Methods. This community-based descriptive cross-sectional study recruited 1008 adults aged 18 years and above in two System Learning Districts of the CHPS+ project. Data collected were analysed using descriptive and inferential statistics. Results. The level of community involvement in CHPS activities was $48.9 \%$ of the population studied. The overall level of positive perception of CHPS services was $51.7 \%$. Community members who were involved in identifying resources $(\mathrm{AOR}=1.86(95 \% \mathrm{CI}=1.17,2.97), p=0.009)$, organising durbars $(\mathrm{AOR}=2.09(95 \%$ $C I=1.12,3.88), p=0.020)$, and preparing sites for outreach services $(\mathrm{AOR}=3.76(95 \% \mathrm{CI}=2.23,6.34), p<0.001)$ were significantly more likely to have positive perceptions of the relevance of CHPS to improving the health status of communities compared to those who were uninvolved. Conclusion. The level of community involvement in CHPS services is low. Ghana may not be able to attain the UHC goal by 2030 through CHPS implementation unless its level of community involvement is markedly improved. Ghana's health sector stakeholders should implement community engagement mechanisms that foster improved worker outreach, expanded use of community gatherings, and more active participation of traditional leaders and grassroots political representatives.
} 


\section{Introduction}

Health is an essential resource for everyday life [1]. Commitment from international organisations such as the World Health Organisation (WHO), United Nations (UN), and the World Bank aims to ensure that all people have access to sufficient and quality healthcare [2]. The 1978 Alma-Ata Declaration advocated community participation and involvement as key concepts of primary healthcare (PHC) [3]. Despite this longstanding goal, access to primary health services remains fragmentary in many developing countries $[2,3]$. The declaration also emphasised the importance of community engagement in the efficient planning, organisation, and functioning of primary healthcare services. Ghana, thus, adopted the Community-based Health Planning and Services (CHPS) in 2000 as a national policy for the provision of PHC services [4]. The CHPS concept brings healthcare to the doorsteps of people by employing the services of health workers living within the community. The health workers deliver convenient healthcare and outreach services within the community [5]. The CHPS system is the key platform for developing UHC for Ghana by improving access and utilisation of PHC services through addressing healthcare delivery inequities [6, 7].

Community involvement is critical to the delivery of healthcare [8]. Studies have shown that community involvement benefits health outcomes in poor populations by significantly improving birth outcomes, access to health services, and service utilisation [9, 10]. In Ghana, community involvement in planning, implementing, and evaluating CHPS activities has improved health outcomes [11]. Though CHPS has been significant in bringing healthcare to the doorsteps of communities, there is limited evidence that community participation is directly linked to improved health outcomes [12]. However, Rifkin [13] later found that, where links were observed, the situations were specific, unpredictable, and not generalisable. As a means to generally improve health outcomes in Ghana through CHPS, the CHPS+ initiative was conceived.

\section{The CHPS+Project}

CHPS + initiative is a health system strengthening program in Ghana helping to achieve the goals of universal health coverage [14]. The CHPS+ is a collaboration project carried out by the Ghana Health Service (GHS); the Mailman School of Public Health, Columbia University, United States of America (USA); the University of Ghana Regional Institute of Population Studies, Ghana; the University of Health and Allied Sciences (UHAS); and the University for Development Studies (UDS) with funding from the Doris Duke Charitable Foundation, USA $[14,15]$. UHAS and UDS serve as training partners on the project. The CHPS+ is a scale-up of the Ghana Essential Health Interventions Programme (GEHIP), which was piloted in three administrative districts of the Upper East Region in Ghana [15]. GEHIP was introduced as a coordinated response to challenges that would strengthen district capabilities to facilitate scale-up of CHPS and improve the content of service delivery. After successful piloting, it was then scaled up to cover more regions in Ghana, thus leading to CHPS+ [15].

The primary goal of CHPS+ is to transfer GEHIP approaches to accelerating and improving CHPS implementation throughout Ghana, by developing learning platforms termed "System Learning Districts" (SLDs) that can serve as a basis for diffusing innovation in CHPS implementation on the GEHIP model. The SLD activities aim to enable other districts to accelerate CHPS coverage and improve service quality. Two of the four CHPS+ SLDs are Nkwanta South Municipality and Central Tongu District in the Volta Region.

The CHPS+ concept involves training and deployment of frontline health workers called community health officers (CHOs) in CHPS zones (made up of a number of communities based on geographical proximity) in rural areas. These CHOs are expected to provide health promotive and disease preventive services, as well as minimal clinical care (such as immunisation, community emergency delivery, referrals, and management of minor ailments) [16]. A key component of the CHPS+ programme is to improve community involvement in PHC delivery. This study was born out of training conducted by the School of Public Health (SPH) of UHAS, for CHOs under the project in the two SLDs. After the training, which was done in August 2018, the CHOs were tasked with reengaging communities in their respective zones in the implementation of CHPS. Three months after the training, this monitoring was conducted to assess the relevance of community involvement in the implementation of CHPS and the community perception of the initiative in improving health outcomes.

\section{Materials and Methods}

3.1. Study Site Description. The study was conducted in the two CHPS+ districts in the Volta Region of Ghana in December 2018. These were the Nkwanta South Municipality and Central Tongu District. The Volta Region is one of the ten administrative regions in Ghana [17]. The region is located between latitudes $50^{\circ} 45^{\prime \prime} \mathrm{N}$ and $80^{\circ} 45^{\prime \prime} \mathrm{N}$ along the southern half of the Eastern border of Ghana, shared with the Republic of Togo [17]. It shares boundaries with Greater Accra, Eastern, and Brong Ahafo regions to the west, Northern Region to the north, and the Gulf of Guinea to the south. The Volta Region is divided into 25 administrative municipal/district assemblies [17]. The region had a 2010 National Population Census total population of 2,549,256 with a projected growth rate of $2.5 \%$.

The Nkwanta South Municipality has a total population of 142,602 and a growth rate of $3 \%$. Nkwanta is the municipal capital. The municipality has 25 demarcated CHPS zones, out of which 21 are functional CHPS zones, in addition to 2 hospitals, 2 health centres, and 1 maternity home [17]. The Central Tongu District, on the other hand, has a total population of 71,302 and a growth rate of $2.4 \%$. The district has Adidome as its capital. There are 18 demarcated CHPS zones, out of which 15 zones are functional, in addition to 1 district hospital, 4 health centres, and 1 private maternity home. A functional CHPS zone supports and 
facilitates emergency referrals in addition to daily home visits and outreach services [5]. Figure 1 presents the map of the study setting.

3.2. Study Design and Population. This was a communitybased descriptive cross-sectional study, conducted in December 2018. The study population comprised male and female adults aged 18 years and above, residing in the selected communities of the two SLDs for at least six months prior to the study, and consenting to participate.

3.3. Sampling. The minimum sample size for the study was 985. However, 1008 community members were studied. The sample size was arrived at using the formula: $n=(Z \alpha / 2)^{2} P(1-P) / e^{2}$, where $n$ is the desired sample size, $Z \alpha / 2$ is the $Z$-score at $95 \%$ confidence interval $=1.96, p$ is the population proportion of interest, and $e$ is the margin of error [18]. A two-stage random sampling technique was used, to select first three communities per SLD and second participants from each of the selected communities. In selecting the communities, the names of all the communities in each zone were written on pieces of paper. The papers were wrapped into small balls and placed in a container. The three wrapped papers, representing the three communities per SLD, were then picked from the container, one at a time, without replacement. The process was repeated until the last community was selected. Then, the WHO cluster random sampling [19] was used at the community level to select the participants. In the selection of households, a geographical landmark (e.g., market) in each community was located. A bottle was then spun, and the direction to which the mouth of the bottle pointed represented the starting point of the survey.

The first household in the direction where the bottle pointed then became the starting household surveyed. Every other 5th household in that direction was then entered into. The number 5 was used based on the sampling fraction derived, based on the estimated population for the study. In this study, a household was defined as a group of people who lived under the same roof and ate together. In each household, a male, a female, or both (18+ years of age) were interviewed once available and consented.

3.4. Data Collection. A pretested interviewer-administered questionnaire was used to collect data for this study. The questionnaire was divided into three sections: Section 100, Section 400, and Section 500. Section 100 focused on the socio-demographic characteristics of the respondents. These comprised age, sex, religion, marital status, ethnicity, educational level, occupation, average monthly income, and National Health Insurance subscription status of respondents. Section 400 focused on community involvement in CHPS activities and captured the following items: community involvement in decision making regarding CHPS activities, setting community health priorities, identifying resources needed for community health services, involvement in the implementation of community health activities, involvement in organising community health durbars, and involvement in preparing sites for outreach services. The last section, Section 500, focused on community perception of the relevance of CHPS, with the following variables: the relevance of CHPS to the improvement of maternal health services in communities, sanitary conditions, health-seeking behaviour of community members, family planning decision making, and overall health status of communities. The section also contained items on the relevance of CHPS to the prevention of common infections as well as being well informed about them.

In the second and third sections, respondents were required to indicate their level of involvement in and perceptions of CHPS on a Likert scale of 4 degrees: strongly agree (coded as 4 ), agree (coded as 3 ), disagree (coded as 2), and strongly disagree (coded as 1). Overall involvement and perception indices variables were computed using the composite scores of the various variables. A dichotomous variable of the degree of involvement was then derived: involved (1) and not involved (0). A second dichotomous variable of the list of perception statements was also derived: agreement (1) and disagreement (0). These variables were then used in running the logistic regression analyses. Reliability analysis was done to determine the appropriateness of the items of the instrument in measuring the expected outcomes, using a Cronbach's alpha analysis [18].

Eighteen research assistants from the SPH of UHAS were trained as field assistants for two days on the data collection tools. During the training, the data collectors were informed about the purpose of the study and taken through all the data collection tools. The training was done to ensure that all data collectors understood how to ask questions to enable the respondents to provide appropriate answers. Pretesting of the instrument was done in one community in the Hohoe Municipality, which was not part of the communities for the main study, on the second day. This was done to ascertain the appropriateness of the questions for the study. The data were collected in December 2018 in each of the SLDs. Four lecturers from SPH-UHAS supervised the data collectors on the field.

3.5. Data Analyses. The questionnaires were checked for completeness, entered into EpiData version 3.1, and then exported into Stata/SE version 14.0 for analysis. Continuous variables were reported as mean \pm standard deviation. Categorical variables were reported as proportions. The Chisquare test was used to determine the association between the dependent variables (level of community involvement in CHPS activities) and the independent variables (sociodemographic characteristics and perception about CHPS services). Statistical significance was considered at $p<0.05$. Logistic regression models were used to determine the strength of associations among variables of interest. Two regression models (I (bivariate) and II (multivariate)) were done.

For community involvement in CHPS activities, the highest score was 24 and the lowest was 6. 


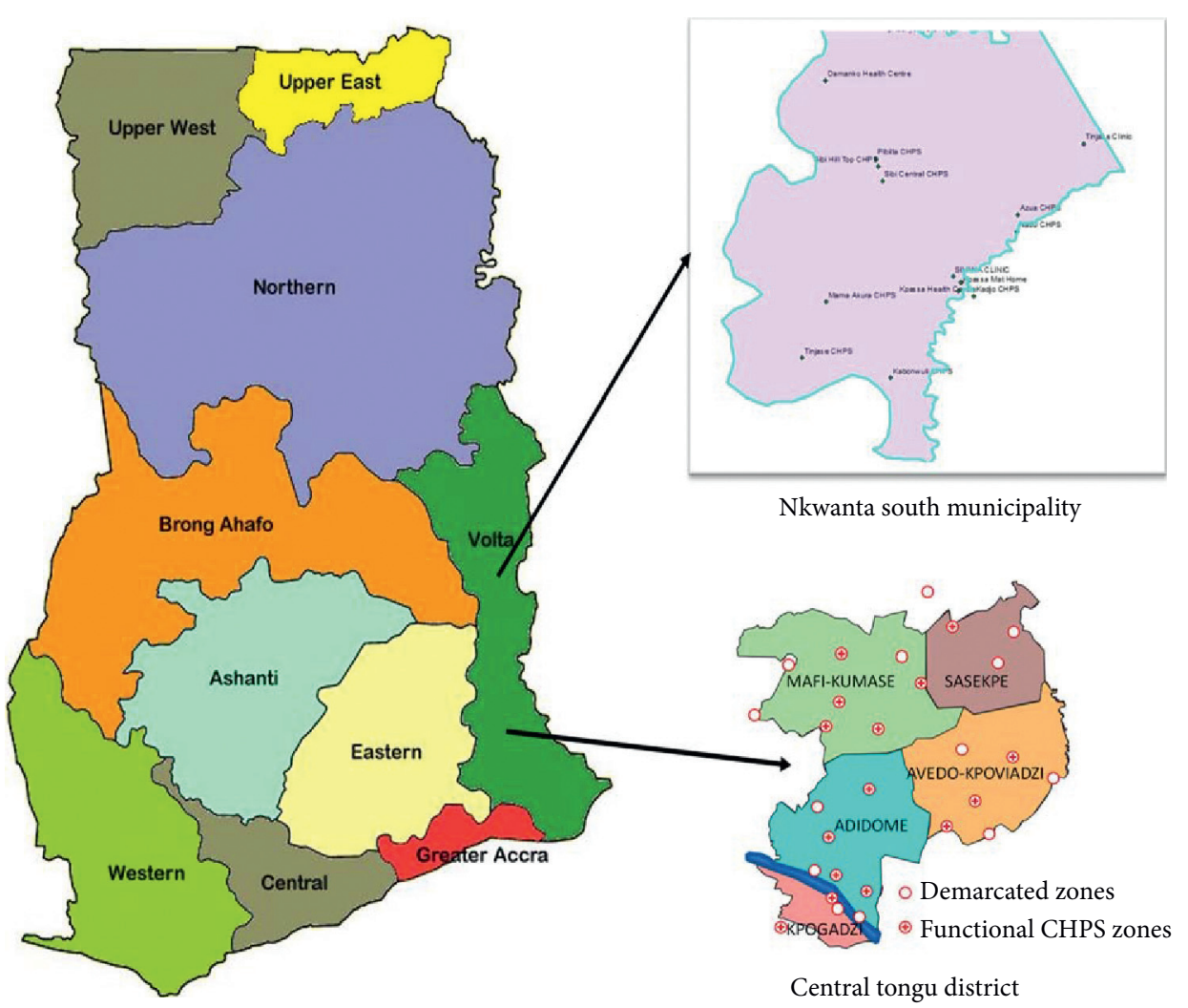

FIgURe 1: Map of study setting.

Cronbach's alpha was used to evaluate the reliability of the questions comprising the composite score, level of community involvement, and perceptions. A Cronbach's alpha coefficient of 0.88 for community involvement in CHPS activities was obtained indicating the appropriateness of the instrument in measuring the expected outcomes [18]. The mean score of community involvement was 19.11. Respondents who had a score less than the mean score were classified as having low level of involvement, and those above the mean were classified as having high level of involvement.

3.6. Ethical Issues. Ethical approval for the study was obtained from the Ghana Health Service (GHS) Ethics Review Committee (ERC) (GHS-ERC) with number GHS-ERC 04/01/2017. Permission was also sought from the directorates of the two SLDs through letters. Permission was also sought from community leaders before the survey was conducted. Informed consent was sought from individual respondents before questionnaires were administered. Names of respondents and their communities were not collected as part of the survey; instead, codes were used as pseudonyms to represent communities.

\section{Results}

4.1. Sociodemographic Characteristics of Respondents. Table 1 describes the background characteristics of survey respondents. A total of 1008 adults aged 18 years and above from two (Central Tongu and Nkwanta South) System Learning Districts (SLDs) were involved in the study with $50 \%$ from each district. The mean age was $39.2 \pm 14.7$. Majority of the respondents were females (56.3\%), Christians (81.8\%), and married (81.1\%). Ewe was the most (64.5\%) represented ethnic group in the two SLDs. A comparative majority of respondents $(34.4 \%)$ attained Junior High School (JHS) level of education. The main occupation of the respondents was farming $(62.1 \%)$. The average monthly income earned by most $(60.3 \%)$ respondents ranged from GHC 100 to 499. Most (53.7\%) of the respondents did not subscribe to the National Health Insurance Scheme (NHIS).

4.2. Community Involvement in CHPS Activities. Figure 2 shows that community involvement in decision making and in setting community health priorities was significantly higher in Nkwanta South than in Central Tongu $(p<0.001)$, respectively. Community involvement in identifying resources needed for community health services, in implementation of community health activities, and in organising health durbars was also significantly higher in the Nkwanta South than in Central Tongu $(p=0.014, p<0.001$, and $p=0.003$, respectively).

Figure 3 presents the level of involvement in CHPS activities as an aggregation of all the involvement variables. Overall, the level of involvement in CHPS activities was $48.9 \%$. While the level of involvement was $53.8 \%$ in Nkwanta South, it was $44 \%$ in Central Tongu. 
TABLE 1: Sociodemographic characteristics of respondents.

\begin{tabular}{|c|c|c|c|}
\hline \multirow{2}{*}{ Variable } & \multicolumn{2}{|c|}{ District } & \multirow{2}{*}{$\begin{array}{c}\text { Total } \\
(n=1008) n(\%)\end{array}$} \\
\hline & Central Tongu $(n=504) n(\%)$ & Nkwanta South $(n=504) n(\%)$ & \\
\hline \multicolumn{4}{|c|}{ ( } \\
\hline Male & $231(45.8)$ & $210(41.7)$ & $441(43.7)$ \\
\hline Female & $273(54.2)$ & $294(58.3)$ & $567(56.3)$ \\
\hline \multicolumn{4}{|l|}{ Mean age (in years) (SD) } \\
\hline \multicolumn{4}{|l|}{ Age group (in years) } \\
\hline$<30$ & $156(31.0)$ & $140(27.8)$ & $296(29.4)$ \\
\hline $30-39$ & $135(26.8)$ & $135(26.8)$ & $270(26.8)$ \\
\hline $40-49$ & $95(18.9)$ & $107(21.3)$ & $202(20.0)$ \\
\hline $50+$ & $118(23.4)$ & $122(24.2)$ & $240(23.8)$ \\
\hline \multicolumn{4}{|l|}{ Religion } \\
\hline Christianity & $451(89.5)$ & $373(74.0)$ & $824(81.8)$ \\
\hline Islam & $19(3.8)$ & $26(5.2)$ & $45(4.5)$ \\
\hline African traditional & $34(6.8)$ & $105(20.9)$ & $139(13.8)$ \\
\hline \multicolumn{4}{|l|}{ Marital status } \\
\hline Married/cohabiting & $404(80.2)$ & $413(81.9)$ & $817(81.1)$ \\
\hline Divorced/separated & $17(3.4)$ & $21(4.2)$ & $38(3.8)$ \\
\hline Widowed & $16(3.2)$ & $27(5.4)$ & $43(4.3)$ \\
\hline Never married/never cohabited & $67(13.3)$ & $43(8.5)$ & $110(10.9)$ \\
\hline \multicolumn{4}{|l|}{ Ethnicity } \\
\hline Ewe & $496(98.4)$ & $154(30.6)$ & $650(64.5)$ \\
\hline Akan & $4(0.8)$ & $31(6.2)$ & $35(3.5)$ \\
\hline Guan & $1(0.2)$ & $258(51.2)$ & $259(25.7)$ \\
\hline Others & $3(0.6)$ & $61(12.1)$ & $64(6.4)$ \\
\hline \multicolumn{4}{|l|}{ Educational level } \\
\hline None & $109(21.6)$ & $177(35.1)$ & $286(28.4)$ \\
\hline Primary & $107(21.2)$ & $90(17.9)$ & $197(19.5)$ \\
\hline JHS & $191(37.9)$ & $156(31.0)$ & $347(34.4)$ \\
\hline Senior high school (SHS) & $70(13.9)$ & $62(12.3)$ & $132(13.1)$ \\
\hline Tertiary & $27(5.4)$ & $19(3.8)$ & $46(4.6)$ \\
\hline \multicolumn{4}{|l|}{ Occupation } \\
\hline Unemployed & $40(7.9)$ & $35(6.9)$ & $75(7.4)$ \\
\hline Trader & $65(12.9)$ & $74(14.7)$ & $139(13.7)$ \\
\hline Farmer & $319(63.3)$ & $307(60.9)$ & $626(62.1)$ \\
\hline Tradesman & $27(5.4)$ & $39(7.7)$ & $66(6.6)$ \\
\hline Seamstress/hairdresser & $24(4.8)$ & $27(5.4)$ & $51(5.1)$ \\
\hline Civil servant & $29(5.8)$ & $22(4.4)$ & $51(5.1)$ \\
\hline \multicolumn{4}{|l|}{ Income (in GHC) } \\
\hline Very low $(<100)$ & $109(21.7)$ & $129(25.6)$ & $238(23.7)$ \\
\hline Low (100-499) & $297(59.2)$ & $310(61.5)$ & $607(60.3)$ \\
\hline High (500-999) & $60(12.0)$ & $46(9.1)$ & $106(10.5)$ \\
\hline Very high $(1000+)$ & $36(7.2)$ & $19(3.8)$ & $55(5.5)$ \\
\hline \multicolumn{4}{|l|}{ NHIS status } \\
\hline Subscriber & $224(44.4)$ & $243(48.2)$ & $467(46.3)$ \\
\hline Nonsubscriber & $280(55.6)$ & $261(51.8)$ & $541(53.7)$ \\
\hline
\end{tabular}

4.3. Association of Sociodemographic Characteristics and Other Predictors with Involvement in CHPS Activities. Table 2 shows that community members in Nkwanta South were significantly 1.51 times $((95 \% \mathrm{CI}=1.16,1.96)$, $p=0.002)$ more likely to be involved in CHPS activities than those in Central Tongu. Community members with SHS educational level were $42 \%$ less likely to be involved in CHPS activities compared to those with no formal education (AOR $=0.58(95 \% \mathrm{CI}=0.36,0.94), p=0.026)$. Seamstresses $/$ hairdressers were also less likely to be involved in CHPS services compared to those who were unemployed (AOR $=0.30(95 \% \mathrm{CI}=0.13,0.70), p=0.005)$. Respondents in the high and very high wealth quintiles (GHC 500-999 and GHC 1000+) were 1.79 ((95\% CI: 1.06, 3.04), $p=0.029)$ and 2.44 times ( $(95 \% \mathrm{CI}=1.21,4.89), p=0.012)$ more likely to be involved in CHPS activities as compared to those who earn very low income ( $<$ GHC 100). Subscribers to NHIS were 1.67 times $((95 \% \mathrm{CI}=1.27,2.19), p<0.001)$ more likely to be involved in CHPS services as compared to nonsubscribers.

4.4. Level of Perception of CHPS. Figure 4 shows that good respondent perceptions of CHPS implementation in relation to the improvement of maternal health services, sanitary conditions, and child health services were significantly 


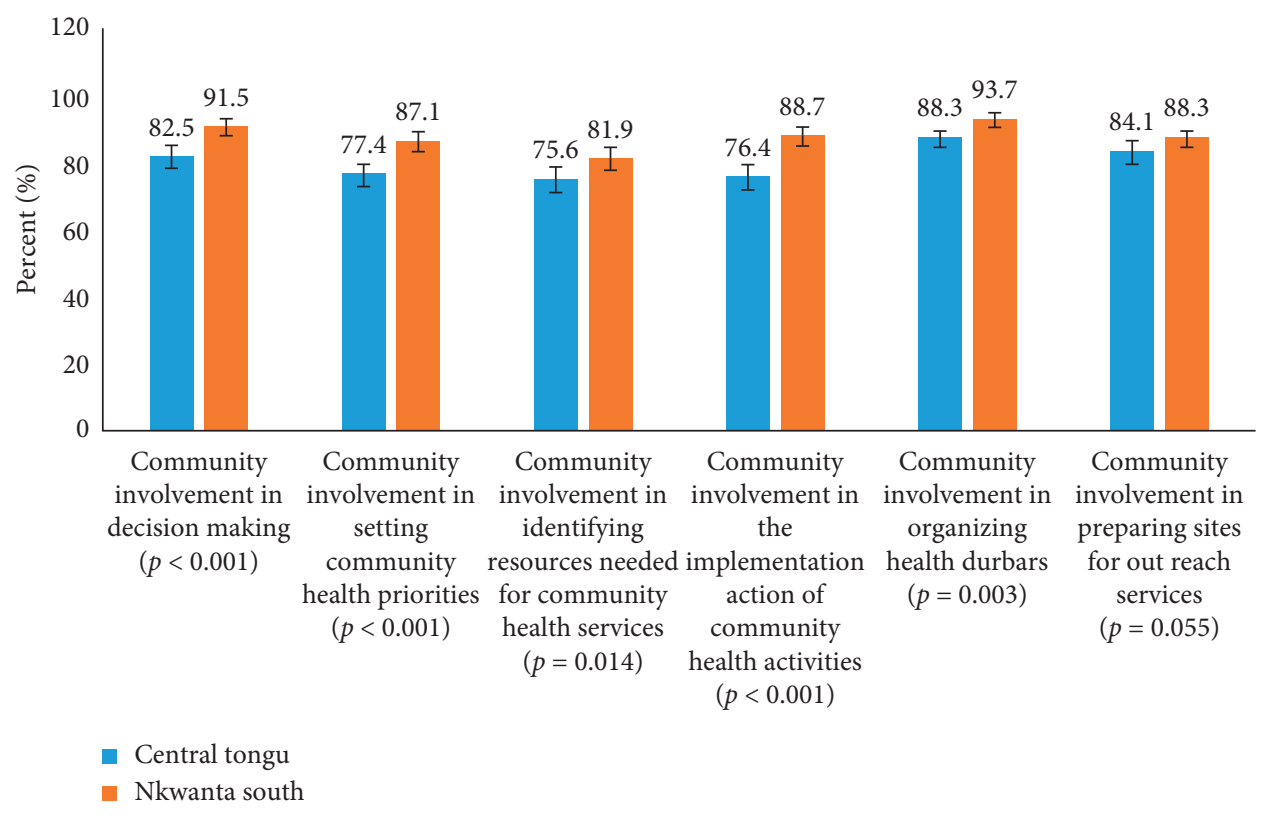

FIGURE 2: Community involvement in CHPS services.

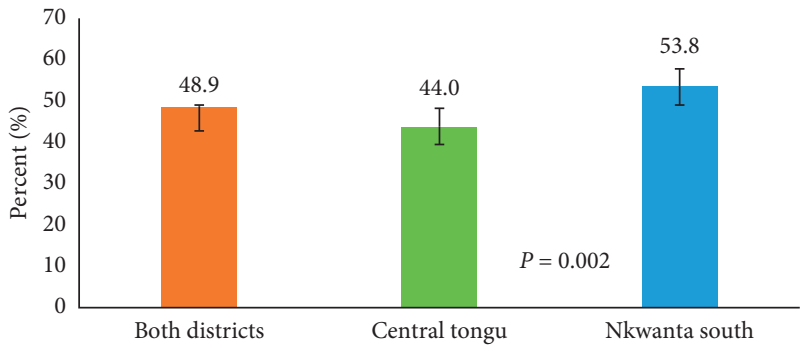

Figure 3: Overall level of involvement in CHPS by district.

higher in Nkwanta South than in Central Tongu $(p=0.039$, $p=0.032$, and $p=0.017$, respectively). Good perception of CHPS implementation and the improvement in community knowledge on the need to prevent common infections and diseases and the overall health status of the community were significantly higher in Nkwanta South than in Central Tongu ( $p=0.002$ and $p=0.031$, respectively).

Figure 5 represents the level of perception of CHPS in the two SLDs as an aggregation of all the perception variables. The overall level of good perception of CHPS was $51.7 \%$. While the level of good perception of CHPS was $59.3 \%$ in Nkwanta South, it was $44 \%$ in Central Tongu.

4.5. Influence of Sociodemographic Characteristics and Involvement on the Perception of CHPS. Table 3 shows that community members in the Nkwanta South were 1.88 times $((95 \% \mathrm{CI}=1.43,2.49), p<0.001)$ more likely to have a good perception about the relevance of CHPS to improving health outcomes compared to those in the Central Tongu. Females were $45 \%$ less likely to have a good perception of the relevance of CHPS compared to males $(\mathrm{AOR}=0.55(95 \%$ $\mathrm{CI}=0.40,0.75), p<0.001)$.
Community members in the low monthly quintile (GHC $100-499)$ were 1.52 times ( $(95 \% \mathrm{CI}=1.04,2.19), p=0.027)$ more likely to have a good perception of the relevance of CHPS compared to those within the very low monthly income quintile ( $<\mathrm{GHC} 100)$. Active subscribers to NHIS were 1.37 times $((95 \% \mathrm{CI}=1.03,1.82), p=0.028)$ more likely to have a good perception of the relevance of CHPS implementation compared to nonsubscribers to NHIS. Respondents who agreed that they are involved in identifying resources, organising durbar, and preparing sites for outreach services were more likely to have good perception of the relevance of CHPS compared to those who did not $(\mathrm{AOR}=1.86(95 \% \mathrm{CI}=1.17,2.97), p=0.009),(\mathrm{AOR}=2.09$ (95\% CI $=1.12,3.88), p=0.020)$, and $(\mathrm{AOR}=3.76(95 \%$ $\mathrm{CI}=2.23,6.34), p<0.001)$, respectively.

\section{Discussion}

This descriptive cross-sectional study examined community involvement in and perceptions of the relevance of CHPS to improving health outcomes in Ghana. Community members in Nkwanta South were 1.51 times more likely to be involved in CHPS activities than those in Central Tongu. They were involved in decision making and setting of community health priorities. They were also involved in identifying resources needed for community health services, implementation action of community health activities, and organising health durbars. This is consistent with a study conducted in the Nkwanta District (now Nkwanta South Municipality and Nkwanta North District) by Azongo [11] who found high involvement of the community members in the planning, implementation, and evaluation of programme activities. The higher level of involvement in Nkwanta South is attributable to the fact that the CHPS concept was piloted there in 1991 before full implementation 
TABLE 2: Influence of sociodemographic characteristics on involvement in CHPS.

\begin{tabular}{|c|c|c|c|c|c|}
\hline \multirow[b]{2}{*}{ Variables } & \multicolumn{2}{|c|}{ Level of involvement } & \multirow{2}{*}{$\begin{array}{c}\text { Chi-square }\left(\chi^{2}\right) \\
\quad(p \text { value })\end{array}$} & \multirow{2}{*}{$\begin{array}{c}\mathrm{COR}(95 \% \mathrm{CI}) \\
p \text { value }\end{array}$} & \multirow{2}{*}{$\begin{array}{c}\text { AOR }(95 \% \mathrm{CI}) \\
p \text { value }\end{array}$} \\
\hline & $\begin{array}{c}\text { Low } \\
\text { involvement }\end{array}$ & $\begin{array}{c}\text { High } \\
\text { involvement }\end{array}$ & & & \\
\hline \multicolumn{6}{|l|}{ District } \\
\hline Central Tongu & $282(54.8)$ & $222(45.0)$ & & \multirow{2}{*}{$\begin{array}{c}\text { Ref. } \\
1.47(1.15,1.89) \\
0.002\end{array}$} & \multirow{2}{*}{$\begin{array}{c}\text { Ref. } \\
1.51(1.16,1.96) \\
0.002\end{array}$} \\
\hline Nkwanta South & $233(45.2)$ & $271(55.0)$ & $9.53(0.002)$ & & \\
\hline \multicolumn{6}{|c|}{ (5) } \\
\hline Male & $209(40.6)$ & $232(47.1)$ & & \multirow{2}{*}{$\begin{array}{c}\text { Ref. } \\
0.76(0.59,0.98) \\
0.038\end{array}$} & \multirow{2}{*}{$\begin{array}{c}\text { Ref. } \\
0.75(0.55,1.00) \\
0.054\end{array}$} \\
\hline Female & $306(59.4)$ & $261(52.9)$ & $4.29(0.038)$ & & \\
\hline \multicolumn{6}{|c|}{ (a) } \\
\hline$<30$ & $171(33.2)$ & $125(25.3)$ & & \multirow{4}{*}{$\begin{array}{c}\text { Ref. } \\
1.28(0.92,1.79) \\
0.134 \\
1.51(1.05,2.16) \\
0.025 \\
1.64(1.16,2.31) \\
0.005\end{array}$} & \multirow{4}{*}{$\begin{array}{cl}\text { Ref. } \\
1.02(0.71,1.48) \\
0.900 \\
1.21(0.79,1.82) \\
0.372 \\
1.18(0.78,1.79) \\
0.432\end{array}$} \\
\hline $30-39$ & $139(27.0)$ & $131(26.6)$ & & & \\
\hline $40-49$ & $96(18.6)$ & $106(21.5)$ & & & \\
\hline $50+$ & $109(21.2)$ & $131(26.6)$ & $9.42(0) 024$. & & \\
\hline \multicolumn{6}{|l|}{ Marital status } \\
\hline Married/cohabiting & $406(78.8)$ & $411(83.3)$ & & \multirow{4}{*}{$\begin{array}{c}\text { Ref. } \\
0.98(0.51,1.89) \\
0.971 \\
1.13(0.61,2.10) \\
0.684 \\
0.56(0.37,0.85) \\
0.007\end{array}$} & \multirow{4}{*}{$\begin{array}{c}\text { Ref. } \\
0.98(0.49,1.94) \\
0.965 \\
1.00(0.52,1.94) \\
0.992 \\
0.67(0.41,1.09) \\
0.104\end{array}$} \\
\hline Divorced/separated & $19(3.7)$ & $19(3.9)$ & & & \\
\hline Widowed & $20(3.9)$ & $23(4.7)$ & & & \\
\hline $\begin{array}{l}\text { Never married and never lived } \\
\text { together }\end{array}$ & $70(13.6)$ & $40(8.1)$ & $7.94(0.047)$ & & \\
\hline \multicolumn{6}{|l|}{ Educational level } \\
\hline None & $137(26.6)$ & $149(30.2)$ & & \multirow{2}{*}{$\begin{array}{c}\text { Ref. } \\
0.83(0.58,1.20) \\
0.344\end{array}$} & \multirow{2}{*}{$\begin{array}{c}\text { Ref. } \\
0.86(0.58,1.26) \\
0.441\end{array}$} \\
\hline Primary & $103(20.0)$ & $94(19.1)$ & & & \\
\hline JHS & $169(32.8)$ & $178(36.1)$ & & $\begin{array}{c}0.96(0.70,1.32) \\
0.841\end{array}$ & $\begin{array}{c}1.02(0.72,1.44) \\
0.933\end{array}$ \\
\hline SHS & $80(15.5)$ & $52(10.6)$ & & $0.59(0.39, .90) 0.016$ & $\begin{array}{c}0.58(0.36,0.94) \\
0.026\end{array}$ \\
\hline Tertiary & $26(5.1)$ & $20(4.0)$ & $7.39(0.117)$ & $\begin{array}{c}0.70(0.37,1.32) \\
0.279\end{array}$ & $\begin{array}{c}0.67(0.23,1.93) \\
0.461\end{array}$ \\
\hline \multicolumn{6}{|l|}{ Occupation } \\
\hline Unemployed & $39(7.6)$ & $36(7.4)$ & & \multirow{6}{*}{$\begin{array}{c}\text { Ref. } \\
0.79(0.45,1.40) \\
0.436 \\
1.20(0.74,1.95) \\
0.440 \\
1.08(0.55,2.09) \\
0.813 \\
0.40(0.19,0.87) \\
0.022 \\
0.75(0.36,1.55) \\
0.450\end{array}$} & \multirow{6}{*}{$\begin{array}{cl} & \text { Ref. } \\
0.53 & (0.27,1.03) \\
0.062 \\
0.79( & (0.43,1.44) \\
0.439 \\
0.68(0.31,1.47) \\
0.325 \\
0.30(0.13,0.70) \\
0.005 \\
0.50(0.17,1.46) \\
0.205\end{array}$} \\
\hline Trader & $80(15.5)$ & $59(11.9)$ & & & \\
\hline Farmer & $296(57.5)$ & $330(66.9)$ & & & \\
\hline Tradesman & $33(6.4)$ & $33(6.7)$ & & & \\
\hline Seamstress/hairdresser & $37(7.2)$ & $14(2.8)$ & & & \\
\hline Civil servant & $30(5.8)$ & $21(4.3)$ & $16.62(0.005)$ & & \\
\hline \multicolumn{6}{|l|}{ Income (GHC) } \\
\hline Very $($ low<100) & $133(25.9)$ & $105(21.3)$ & & \multirow{4}{*}{$\begin{array}{c}\text { Ref. } \\
1.19(0.88,1.61) \\
0.241 \\
1.65(1.04,2.62) \\
0.033 \\
1.76(0.97,3.19) \\
0.061\end{array}$} & \multirow{4}{*}{$\begin{array}{cl} & \text { Ref. } \\
1.23 & (0.86,1.75) \\
0.254 \\
1.79 & (1.06,3.04) \\
& 0.029 \\
2.44 & (1.21,4.89) \\
& 0.012\end{array}$} \\
\hline Low (100-499) & $312(60.7)$ & $295(60.0)$ & & & \\
\hline High (500-999) & $46(8.9)$ & $60(12.2)$ & & & \\
\hline Very high $(1000+)$ & $23(4.5)$ & $32(6.5)$ & $6.61(0.085)$ & & \\
\hline \multicolumn{6}{|l|}{ NHIS status } \\
\hline Nonsubscriber & $301(58.5)$ & $240(48.7)$ & & Ref. & Ref. \\
\hline Subscriber & $214(41.5)$ & $253(51.3)$ & $9.65(0.002)$ & $\begin{array}{l}1.48(1.15,1.90) \\
0.002\end{array}$ & $\begin{aligned} 1.67 & (1.27,2.19) \\
& <0.001\end{aligned}$ \\
\hline
\end{tabular}




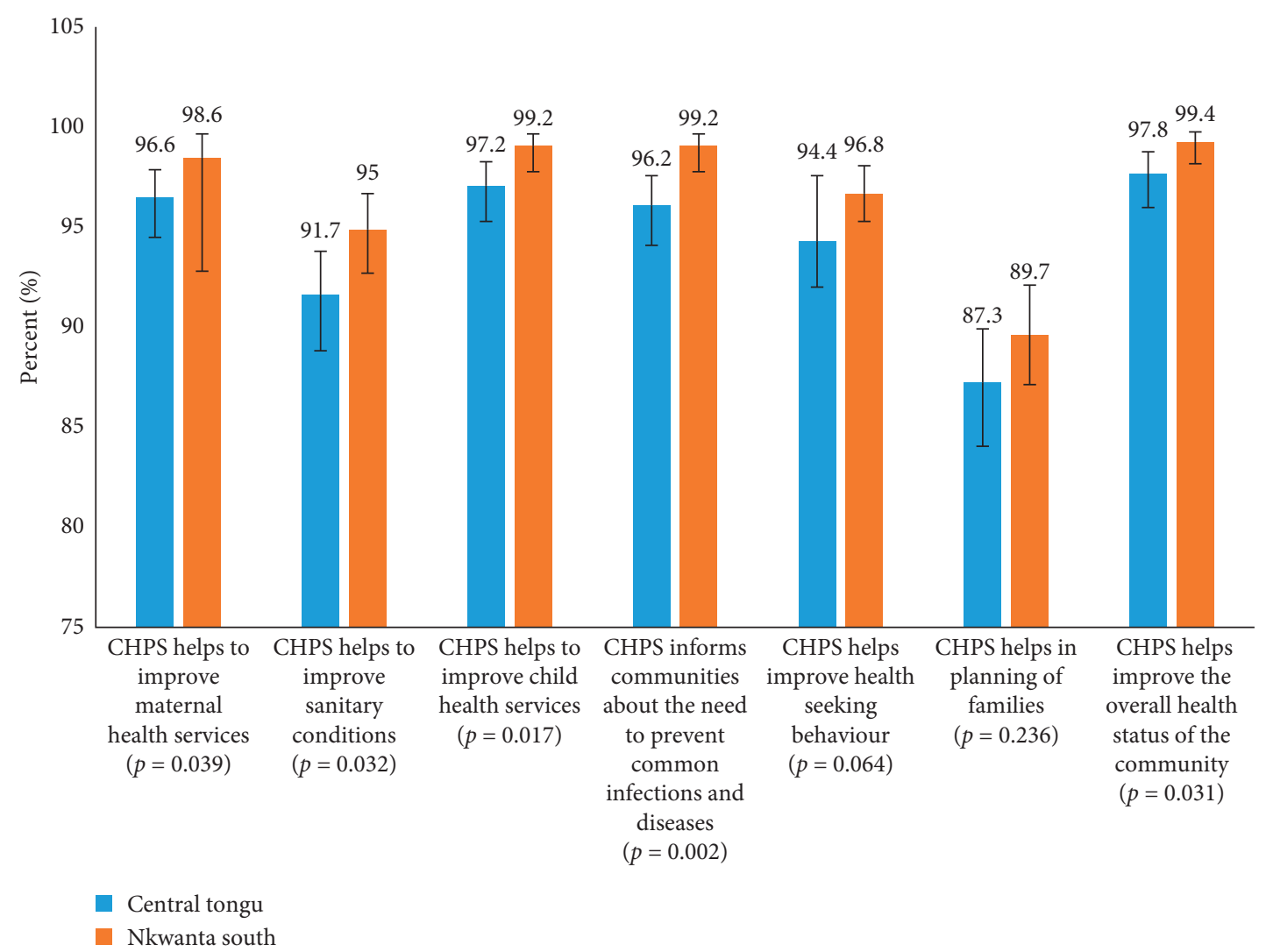

FIgURE 4: Community perception of CHPS services.

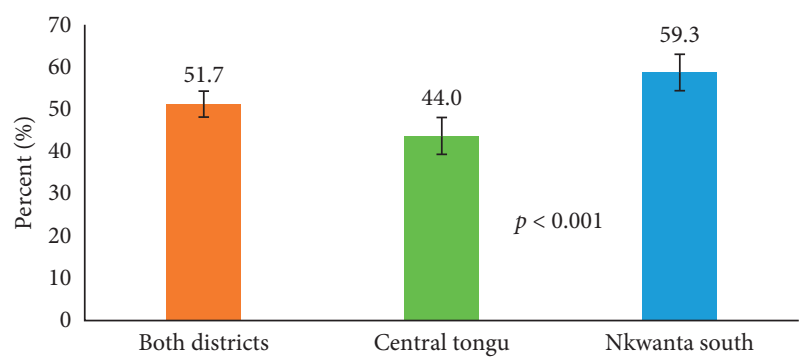

FIgURE 5: Overall level of perception of CHPS.

in Ghana [11], hence their better understanding and appreciation of the CHPS concept.

We also found that community members who earn appreciable monthly income, those in the high or very high income quintile, were more likely to be involved in CHPS services than those who earned a very low income. This has been explained by Howard-Grabman et al. [20] in their study to ascertain factors affecting effective community participation in maternal and newborn health programme planning, implementation, and quality of care interventions, where funding was found to influence involvement. Thus, individuals with appreciable income levels are more likely to be involved in communal health-related issues, especially in health programmes that require communities to contribute to the funding of such programmes. Hence, as the CHPS concept requires communities to support the construction and running of health facilities, it is possible that individuals who consider themselves to be poor would not be deeply involved in the implementation of the concept in their respective communities as they might not be able to contribute financially when they have to do so.

Moreover, active subscribers to NHIS were found to be more likely (1.5 times) to be involved in CHPS compared to nonsubscribers. Nonsubscription to the NHIS could be a result of lack of financial means to do so since subscription attracts a fee. Thus, the less involvement of respondents from the lower income quintile in CHPS explains why non-NHISsubscribers were also less involved. Hossain et al. [21] blamed this on the lack of community development. The authors took the view that empowering communities and individuals to obtain self-reliance and control over factors that affect their health such as the ability to subscribe to health insurance, is likely to improve involvement in health initiatives.

With reference to perception, it was found that community members in the Nkwanta South were more likely to have a good perception of CHPS than those in the Central Tongu District. As posited by Fredriksson et al. [22], one's level of involvement can influence perception of primary healthcare delivery and relevance, such as the CHPS concept. It was thus obvious that, with higher levels of involvement, community members in Nkwanta South also had more positive perceptions of the role of CHPS in improving their health status compared to those in Central Tongu. It was also 
TABLE 3: Influence of sociodemographic characteristics and involvement on the perception of CHPS.

\begin{tabular}{|c|c|c|c|c|c|}
\hline \multirow[b]{2}{*}{ Variables } & \multicolumn{2}{|c|}{ Level of perception } & \multirow[b]{2}{*}{$\begin{array}{c}\text { Chi-square }\left(\chi^{2}\right) \\
\quad p \text { value }\end{array}$} & \multirow[b]{2}{*}{$\begin{array}{c}\text { COR }(95 \% \mathrm{CI}) \\
\quad p \text { value }\end{array}$} & \multirow[b]{2}{*}{$\begin{array}{c}\text { AOR }(95 \% \mathrm{CI}) \\
p \text { value }\end{array}$} \\
\hline & $\begin{array}{l}\text { Poor perception } \\
(n=487) n(\%)\end{array}$ & $\begin{array}{l}\text { Good perception } \\
(n=521) n(\%)\end{array}$ & & & \\
\hline \multicolumn{6}{|l|}{ District } \\
\hline Central Tongu & $282(57.9)$ & $222(42.6)$ & & \multirow{2}{*}{$\begin{array}{c}\text { Ref. } \\
1.85(1.44,2.37) \\
<0.001\end{array}$} & \multirow{2}{*}{$\begin{array}{c}\text { Ref. } \\
1.88(1.43,2.49) \\
<0.001\end{array}$} \\
\hline Nkwanta South & $205(42.1)$ & $299(57.4)$ & $23.55(<0.001)$ & & \\
\hline \multicolumn{6}{|c|}{ (2) } \\
\hline Male & $188(38.6)$ & $253(48.6)$ & & \multirow{2}{*}{$\begin{array}{c}\text { Ref. } \\
0.66(0.51,0.86) \\
0.001\end{array}$} & \multirow{2}{*}{$\begin{array}{c}\text { Ref. } \\
0.55(0.40 \\
0.75)<0.001\end{array}$} \\
\hline Female & $299(61.4)$ & $268(51.4)$ & $10.14(0.001)$ & & \\
\hline \multicolumn{6}{|l|}{ Age group } \\
\hline$<30$ & $162(33.3)$ & $134(25.7)$ & & \multirow{2}{*}{$\begin{array}{c}\text { Ref. } \\
1.21(0.86,1.68) \\
0.261\end{array}$} & \multirow{2}{*}{$\begin{array}{c}\text { Ref. } \\
0.90(0.61,1.33) \\
0.623\end{array}$} \\
\hline $30-39$ & $135(27.7)$ & $135(26.9)$ & & & \\
\hline $40-49$ & $88(18.1)$ & $114(21.9)$ & & $\begin{array}{c}1.56(1.09,2.24) \\
0.015\end{array}$ & $\begin{array}{c}1.01(0.66,1.54) \\
0.953\end{array}$ \\
\hline $50+$ & $102(20.9)$ & $138(26.4)$ & $10.26(0.016)$ & $\begin{array}{c}1.63(1.16,2.30) \\
0.005\end{array}$ & $\begin{array}{l}1.08(0.70 \\
1.66) 0.720\end{array}$ \\
\hline \multicolumn{6}{|l|}{ Marital status } \\
\hline Married/cohabiting & $374(76.8)$ & $443(85.0)$ & & \multirow{2}{*}{$\begin{array}{c}\text { Ref. } \\
0.68(0.35,1.31) \\
0.254\end{array}$} & \multirow{2}{*}{$\begin{array}{c}\text { Ref. } \\
0.59(0.29 \\
1.20) 0.147\end{array}$} \\
\hline Divorced/separated & $21(4.3)$ & $17(3.3)$ & & & \\
\hline Widowed & $24(4.9)$ & $19(3.7)$ & & $\begin{array}{l}0.66(0.36 \\
1.24) 0.201\end{array}$ & $\begin{array}{c}0.69(0.34,1.41) \\
0.315\end{array}$ \\
\hline $\begin{array}{l}\text { Never married and never lived } \\
\text { together }\end{array}$ & $68(14.0)$ & $42(8.0)$ & $11.84(0.008)$ & $\begin{array}{l}0.52(0.34 \\
0.78) 0.002\end{array}$ & $\begin{array}{c}0.69(0.42,1.14) \\
0.147\end{array}$ \\
\hline \multicolumn{6}{|l|}{ Occupation } \\
\hline Unemployed & $45(9.2)$ & $30(5.8)$ & & \multirow{2}{*}{$\begin{array}{c}\text { Ref. } \\
1.57(0.88 \\
2.76) 0.122\end{array}$} & \multirow{2}{*}{$\begin{array}{c}\text { Ref. } \\
1.26(0.63 \\
2.52) 0.514\end{array}$} \\
\hline Trading & $68(13.9)$ & $71(13.6)$ & & & \\
\hline Farming & $274(56.3)$ & $352(67.5)$ & & $\begin{array}{c}1.92(1.18,3.13) \\
0.008\end{array}$ & $\begin{array}{l}1.29(0.69 \\
2.39) 0.426\end{array}$ \\
\hline Tradesman & $36(7.4)$ & $30(5.8)$ & & $\begin{array}{l}1.25(0.64 \\
2.44) 0.514\end{array}$ & $\begin{array}{l}0.64(0.28 \\
1.43) 0.279\end{array}$ \\
\hline Seamstress/hairdresser & $33(6.8)$ & $18(3.5)$ & & $\begin{array}{c}0.81(0.39,1.71) \\
0.594\end{array}$ & $\begin{array}{l}0.70(0.30 \\
1.65) \\
0.422\end{array}$ \\
\hline Civil servant & $31(6.4)$ & $20(3.8)$ & $18.98(0.002)$ & $\begin{array}{l}0.97(0.47 \\
2.00) 0.930\end{array}$ & $\begin{array}{l}0.55(0.23 \\
1.32) 0.186\end{array}$ \\
\hline \multicolumn{6}{|l|}{ Income (in GHC) } \\
\hline Very low $(<100)$ & $133(25.9)$ & $105(21.3)$ & & \multirow{2}{*}{$\begin{array}{c}\text { Ref. } \\
1.62(1.19,2.19) \\
0.002\end{array}$} & \multirow{2}{*}{$\begin{array}{c}\text { Ref. } \\
1.52(1.04,2.19) \\
0.027\end{array}$} \\
\hline Low (100-499) & $312(60.7)$ & $295(60.0)$ & & & \\
\hline High (500-999) & $46(8.9)$ & $60(12.2)$ & & $\begin{array}{c}1.43(0.91,2.27) \\
0.121\end{array}$ & $\begin{array}{c}1.27(0.74,2.19) \\
0.381\end{array}$ \\
\hline Very high (1000+) & $23(4.5)$ & $32(6.5)$ & $10.05(0.018)$ & $\begin{array}{l}1.60(0.88 \\
2.88) 0.118\end{array}$ & $\begin{array}{l}1.67(0.82 \\
3.38) 0.158\end{array}$ \\
\hline \multicolumn{6}{|l|}{ NHIS status } \\
\hline Nonsubscriber & $279(57.3)$ & $262(50.3)$ & & \multirow{2}{*}{$\begin{array}{c}\text { Ref. } \\
1.32(1.03,1.69) \\
0.026\end{array}$} & \multirow{2}{*}{$\begin{array}{c}\text { Ref. } \\
1.37(1.03,1.82) \\
0.028\end{array}$} \\
\hline Active subscriber & $208(42.7)$ & $259(49.7)$ & $4.96(0.026)$ & & \\
\hline \multicolumn{6}{|l|}{ Involvement in decision making } \\
\hline Disagree & $91(18.7)$ & $40(7.7)$ & & Ref. & Ref. \\
\hline Agree & $396(81.3)$ & $481(92.3)$ & $26.97(<0.001)$ & $\begin{array}{c}2.76(1.86,4.10) \\
<0.001\end{array}$ & $\begin{array}{c}0.95(0.51,1.77) \\
0.876\end{array}$ \\
\hline $\begin{array}{l}\text { Involvement in setting community } \\
\text { health priorities }\end{array}$ & & & & & \\
\hline Disagree & $122(25.1)$ & $57(10.9)$ & & Ref. & Ref. \\
\hline Agree & $365(74.9)$ & $465(89.1)$ & $34.31(<0.001)$ & $\begin{aligned} 2.72 & (1.93,3.83) \\
& <0.001\end{aligned}$ & $\begin{array}{l}1.08(0.62 \\
1.89) 0.777\end{array}$ \\
\hline
\end{tabular}


TABLE 3: Continued.

\begin{tabular}{|c|c|c|c|c|c|}
\hline \multirow[b]{2}{*}{ Variables } & \multicolumn{2}{|c|}{ Level of perception } & \multirow{2}{*}{$\begin{array}{c}\text { Chi-square }\left(\chi^{2}\right) \\
p \text { value }\end{array}$} & \multirow[b]{2}{*}{$\begin{array}{c}\text { COR }(95 \% \mathrm{CI}) \\
p \text { value }\end{array}$} & \multirow[b]{2}{*}{$\begin{array}{c}\text { AOR }(95 \% \mathrm{CI}) \\
p \text { value }\end{array}$} \\
\hline & $\begin{array}{c}\text { Poor perception } \\
(n=487) n(\%)\end{array}$ & $\begin{array}{l}\text { Good perception } \\
(n=521) n(\%)\end{array}$ & & & \\
\hline \multicolumn{6}{|c|}{$\begin{array}{l}\text { Involvement in identifying } \\
\text { resources }\end{array}$} \\
\hline Disagree & $148(30.4)$ & $66(12.7)$ & & \multirow{2}{*}{$\begin{array}{c}\text { Ref. } \\
3.0(2.18,4.15) \\
<0.001\end{array}$} & \multirow{2}{*}{$\begin{array}{c}\text { Ref. } \\
1.86(1.17,2.97) \\
0.009\end{array}$} \\
\hline Agree & $339(69.6)$ & $455(87.3)$ & $47.27(<0.001)$ & & \\
\hline \multicolumn{6}{|c|}{$\begin{array}{l}\text { Involvement in the implementation } \\
\text { action }\end{array}$} \\
\hline Disagree & $116(23.8)$ & $60(11.5)$ & & \multirow{2}{*}{$\begin{array}{c}\text { Ref. } \\
2.40(1.71,3.37) \\
<0.001\end{array}$} & \multirow{2}{*}{$\begin{array}{c}\text { Ref. } \\
0.84(0.52 \\
1.37) 0.501\end{array}$} \\
\hline Agree & $371(76.2)$ & $461(88.5)$ & $26.43(<0.001)$ & & \\
\hline \multicolumn{6}{|c|}{$\begin{array}{l}\text { Involvement in the organising } \\
\text { durbar }\end{array}$} \\
\hline Disagree & $73(15.0)$ & $18(3.5)$ & & \multirow{3}{*}{$\begin{array}{c}\text { Ref. } \\
4.92(2.89 \\
8.38)<0.001\end{array}$} & \multirow{3}{*}{$\begin{array}{c}\text { Ref. } \\
2.09(1.12,3.88) \\
0.020\end{array}$} \\
\hline Agree & $414(85.0)$ & $503(96.5)$ & $40.77(<0.001)$ & & \\
\hline \multicolumn{4}{|c|}{$\begin{array}{l}\text { Involvement in preparing sites for } \\
\text { outreach services }\end{array}$} & & \\
\hline Disagree & $113(23.2)$ & $26(5.0)$ & & Ref. & Ref. \\
\hline Agree & $374(76.8)$ & 95.0 & $70.23(<0.001)$ & $\begin{aligned} 5.75 & (3.67 \\
8.99) & <0.001\end{aligned}$ & $\begin{aligned} 3.76 & (2.23 \\
6.34) & <0.001\end{aligned}$ \\
\hline
\end{tabular}

found that community members with high monthly income were more likely to have a good perception of CHPS compared to those with very low monthly incomes. This is because involving community members in CHPS activities such as resources mobilisation requires those who earn significant amount to contribute; hence their voices are also likely to be considered in terms of decision making. The good perception of high income earners translates into more involvement in CHPS as established in this study.

Community members in this study had a positive perception of CHPS implementation as contributor to improving maternal health services, sanitary conditions, and child health services. CHPS was also perceived to improve community knowledge on the need to prevent common infections and diseases, and the overall health status of the community was also significantly higher in Nkwanta South than in Central Tongu. This finding was consistent with research conducted elsewhere in Ghana showing that communities experiencing immunisation of children, health education given to mothers on childcare, growth monitoring of children, and accessible healthcare were associated with general beliefs that CHPS implementation contributed to these health benefits [9].

Community members who had positive perceptions of CHPS were more likely to be involved in CHPS activities compared to those with poor perception. Results are consistent with findings from research in southern Ghana showing that males in communities with functioning CHPS were more involved in family planning services than those in communities with poorly functioning CHPS [9]. Moreover, involvement of NHIS subscribers in CHPS was associated with positive perceptions of CHPS. Active NHIS subscribers were 1.37 times more likely to have a good perception of the relevance of CHPS compared to nonsubscribers. This could be explained by the fact that active subscribers to NHIS utilised more CHPS services as they qualified to do so and thus were benefiting from the concept, compared to nonsubscribers who might not be using CHPS services, thereby having some level of resentment, leading to the bad perception of the concept.

In our study, community members who were involved in various CHPS activities perceived that CHPS implementation has improved health status, especially in relation to overall health status, child health, maternal health, and health-seeking behaviour. The more the community members are involved in CHPS, the more they are likely to have a good perception of the initiative. For instance, community members who were involved in identifying resources, organising durbar, and preparing the site for outreach services were 1.86, 2.09, and 3.76 times more likely to have good perception of the CHPS compared to those who were not involved $(p=0.009$, $p=0.020$, and $p<0.001$, respectively). Other research, such as results reported by Bath and Wakerman [23], has shown that community participation in primary healthcare is associated with intermediate health outcomes such as responsiveness, leading to good perception and better health outcomes. It could thus be argued that community members' involvement made them understand and appreciate the services $\mathrm{CHO}$ were rendering in their respective CHPS zones, leading to the good perception of CHPS. Thus, community involvement made members better understand and appreciate the CHPS concept.

\section{Conclusion}

The level of community involvement in CHPS services is low. Community members in Nkwanta South are more involved in the implementation of CHPS activities and have better perception of CHPS activities than those in Central 
Tongu. Community members who are involved in the implementation of CHPS activities also have better perception than those who are not involved. Subscribers to NHIS are more involved in activities of CHPS than nonsubscribers, and those involved have better perception of CHPS. Ghana may not attain its UHC goal by the year 2030 unless community engagement components of the programme are improved.

To ensure the attainment of health for all through CHPS implementation by the year 2030, Ghana's health sector stakeholders should implement community engagement mechanisms that foster improved worker outreach, expanded use of community gatherings, and more active participation of traditional leaders and grassroots political representatives. Such interventions could include outreach to social networks, improved communication with men, increased attention to community events such as durbars, better collaboration with traditional leaders, and involvement of District Assembly Members in CHPS communication activities. Also, appropriate funding models should be instituted for community members in the low income quintiles who are likely to be NHIS nonsubscribers to enable them access CHPS services which have cost components.

6.1. Limitation. A major limitation of our study is that it did not ascertain the reasons behind the poor perception of CHPS among community members and hence could not properly recommend how to improve the community members' perception of CHPS.

\section{Abbreviations}

$\begin{array}{ll}\text { UN: } & \text { United Nations } \\ \text { PHC: } & \text { Primary healthcare } \\ \text { WHO: } & \text { World Health Organisation } \\ \text { CHPS: } & \text { Community-based Health Planning and } \\ & \text { Services } \\ \text { CHOs: } & \text { Community Health Officers } \\ \text { NHIS: } & \text { National Health Insurance Scheme } \\ \text { SLDs: } & \text { System Learning Districts } \\ \text { CU: } & \text { Columbia University } \\ \text { UDS: } & \text { University of Development Studies } \\ \text { USA: } & \text { United States of America } \\ \text { UHAS: } & \text { University of Health and Allied Sciences } \\ \text { SPH: } & \text { School of Public Health } \\ \text { SPH- } & \text { School of Public Health of the University of } \\ \text { UHAS: } & \text { Health and Allied Sciences } \\ \text { GEHIP: } & \text { Ghana Essential Health Interventions } \\ & \text { Programme } \\ \text { JHS: } & \text { Junior High School } \\ \text { SHS: } & \text { Senior High School } \\ \text { GHS: } & \text { Ghana Health Service } \\ \text { ERC: } & \text { Ethics Review Committee. }\end{array}$

\section{Data Availability}

The primary data used to support the findings of this study are included within the article.

\section{Conflicts of Interest}

The authors declare that they have no conflicts of interest.

\section{Authors' Contributions}

MK, HA, and JG conceived the study. MK, HA, and MA did the data analysis and wrote the Materials and Methods section. MK, HA, MA, EM, FYA, EET, JK, GAA, GAA, and JOG were responsible for the initial draft of the manuscript. MK, HA, MA, EM, FYA, EET, JK, GAA, NAA, LAB, JSA, RG, AAB, TL, JKA, JFP, and JOG revised the manuscript for intellectual content and gave consent for the version to be published. All authors have read and approved the final manuscript and agreed to be accountable for all aspects of the work.

\section{Acknowledgments}

The authors acknowledge the support of the other CHPS+ project collaborators: Ghana Health Service; the Mailman School of Public Health of Columbia University, USA; the University of Ghana Regional Institute of Population Studies, Ghana. The authors are also grateful to the Doris Duke Charitable Foundation, USA, for providing funding for the study. Their appreciation also goes to the health workers and community members involved in the survey from the two SLDs: Central Tongu and Nkwanta South. The CHPS+ project was supported by grants of the Doris Duke Charitable Foundations' African Health Initiative to the Mailman School of Public Health, Columbia University, USA, and the University of Allied and Health Sciences (UHAS) School of Public Health.

\section{References}

[1] World Health Organization, "Tracking universal health coverage," 2017 Global Monitoring Report, World Health Organization, Geneva, Switzerland, 2017.

[2] T. Boerma, J. Requejo, C. G. Victora et al., "to 2030: tracking progress towards universal coverage for reproductive, maternal, newborn, and child health," The Lancet, vol. 391, no. 10129, pp. 1538-1548, 2018.

[3] WHO, "Report of the international conference on primary health care," Alma-Ata: WHO, Geneva, Switzerland, 1978.

[4] M. Kweku, H. Amu, A. Awolu et al., "Community-based health planning and services plus programme in Ghana: a qualitative study with stakeholders in two systems learningd on improving the implementation of primary health care," PLoS One, vol. 15, Article ID 0226808, 2020.

[5] AA. Bawah, JK. Awoonor-Williams, PO. Asuming et al., "The child survival impact of the Ghana essential health interventions program: a health systems strengthening plausibility trial in Northern Ghana," PLoS One, vol. 14, no. 6, 2019.

[6] J. F. Phillips, F. N. Binka, J. K. Awoonor-Williams, F. K. Nyonator, and A. A. Bawah, "Ghana: four decades of community-based primary health care development," in Proceedings of the Health for All-Success Stories from Countries that Transformed People's Health: Essays to Recognize the 40th Anniversary of the Alma Ata Conference, Alma Ata, Kazakhstan, 2018. 
[7] A. A. Bawah, J. F. Phillips, P. O. Asuming et al., "Does the provision of community health services offset the effects of poverty and low maternal educational attainment on childhood mortality? An analysis of the equity effect of the Navrongo experiment in Northern Ghana," SSM-Population Health, vol. 7, Article ID 100335, 2019.

[8] L. Baatiema, M. Skovdal, S. Rifkin, and C. Campbell, "Assessing participation in a community-based health planning and services programme in Ghana," BMC Health Services Research, vol. 13, no. 1, p. 233, 2013.

[9] P. B. Adongo, P. Tapsoba, J. F. Phillips et al., "The role of community-based health planning and services strategy in involving males in the provision of family planning services: a qualitative study in Southern Ghana," Reproductive Health, vol. 10, no. 1, p. 36, 2013.

[10] R. Preston, H. Waugh, J. Taylor, and S. Larkins, "The benefits of community participation in rural health service development: where is the evidence?" in Proceedings of the National Rural Health Conference, Cairns, Australia, May 2009.

[11] T. B. Azongo, "Community participation in the community based health planning and services (CHPS) programme in Nkwanta district, Volta region, Ghana," Doctoral dissertation, University of Ghana, Accra, Ghana, 2002.

[12] S. B. Rifkin, "Lessons from community participation in health programmes: a review of the post Alma-Ata experience," International Health, vol. 1, no. 1, pp. 31-36, 2009.

[13] S. B. Rifkin, "Examining the links between community participation and health outcomes: a review of the literature," Health Policy and Planning, vol. 29, no. 2, pp. ii98-ii106, 2014.

[14] J. K. Awoonor-Williams, J. F. Phillips, and A. A. Bawah, "Catalyzing the scale-up of community-based primary healthcare in a rural impoverished region of northern Ghana," The International Journal of Health Planning and Management, vol. 31, no. 4, pp. 273-289, 2016

[15] J. F. Phillips, J. K. Awoonor-Williams, A. A. Bawah et al., "What do you do with success? The science of scaling up a health system strengthening intervention in Ghana," BMC Health Services Research, vol. 18, no. 1, p. 484, 2018.

[16] S. Ntsua, P. Tapsoba, G. Q. Asare, and F. K. Nyonator, Repositioning Community-Based Family Planning in Ghana: A Case Study of Community-Based Health Planning and Services (CHPS), The Population Council, Inc., Washington, DC, USA, 2012.

[17] Ghana Statistical Services, "Population and housing census report 2010," Accra: Ghana Statistical Service (GSS), Accra, Ghana, 2013.

[18] K. S. Taber, "The use of cronbach's alpha when developing and reporting research instruments in science education," Research in Science Education, vol. 48, no. 6, pp. 1273-1296, 2018.

[19] R. H. Henderson and T. Sundaresan, "Cluster sampling to assess immunization coverage: review of experience with a simplified method," Bull World Health Organization, vol. 60, pp. 253-260, 1982.

[20] L. Howard-Grabman, A. S. Miltenburg, C. Marston, and A. Portela, "Factors affecting effective community participation in maternal and newborn health programme planning, implementation and quality of care interventions," $B M C$ Pregnancy and Childbirth, vol. 17, no. 1, p. 268, 2017.

[21] S. M. Hossain, A. Bhuiya, A. R. Khan, and I. Uhaa, "Community development and its impact on health: South Asian experience," BMJ, vol. 328, no. 7443, pp. 830-833, 2004.

[22] M. Fredriksson, M. Eriksson, and J. Q. Tritter, "Involvement that makes an impact on healthcare: perceptions of the
Swedish public," Scandinavian Journal of Public Health, vol. 46, no. 4, pp. 471-477, 2018.

[23] J. Bath and J. Wakerman, "Impact of community participation in primary health care: what is the evidence?" Australian Journal of Primary Health, vol. 21, no. 1, pp. 2-8, 2015.

[24] Ghana Statistical Service (GSS), Projected Population by District and Sex, Volta Region, 2015-2020, Ghana Statistical Service, Accra, Ghana, 2018.

[25] W. G. Coehran, Sampling Techniques, Wiley, New York, NY, USA, 3rd edition, 1977. 